\title{
KAMERA SEBAGAI ALAT OPERASI MALE GAZE: ANALISIS MALE GAZE DALAM FILM HOROR "PACAR HANTU PERAWAN"
}

\author{
Diyah Ayu Karunianingsih \\ Sekolah Tinggi Multi Media (MMTC) Yogyakarta \\ Jalan Magelang Km. 6, Yogyakarta 55284 \\ No.HP.: 081931740514,E-mail: ayudiyah1802@gmail.com
}

\begin{abstract}
Abstrak
Kehadiran perempuan dalam sebuah film horor dapat dilihat dari bagaimana perempuan direpresentasikan dan diposisikan. Film yang dianalisis adalah film horor berjudul Pacar Hantu Perawan. Menurut Lauretis teknik sinematik mengonstruksi perempuan sebagai objek hasrat pandangan bagi penonton dengan menggarisbawahi representasi tubuh perempuan sebagai sisi utama seksualitas dan kesenangan visual. Dalam tulisan ini dianalisis teknik sinematik terutama kamera dengan berbagai pilihan tipe pengambilan gambar (type of shot) yang digunakan. Analisis juga dilakukan terhadap teknik pencahayaan (lighting) dan pilihan kostum. Dari hasil analisis diketahui bahwa teknik sinematik baik teknik pengambilan gambar (type of shot) maupun pencahayaan digunakan untuk melancarkan hasrat memandang laki-laki (male gaze) dan mengeksploitasi tubuh perempuan demi kesenangan visual. Kamera digunakan sebagai alat beroperasinya hasrat memandang (voyerist gaze). Perempuan diposisikan sebagai objek bagi pandangan laki-laki yang patuh terhadap tatapan mata kamera (tatapan mata laki-laki). Teknik sinematik mengonstuksi perempuan sebagai objek hasrat pandangan bagi orang-orang di balik produksi dan penonton.
\end{abstract}

Kata kunci: male gaze, teknik sinematik, perempuan, objek seksualitas

\section{Abstract}

Camera as a Tool of Male Gaze Operations: The Analysis of Male Gaze in Horror Film "Pacar Hantu Perawan". The presence of women in a horror movie can be seen from how women are represented and positioned. The title of The film being analyzed is 'Pacar Hantu Perawan'. According to Lauretis, cinematic technique is used to construct women as an object of eyeing desire for the audience by highlighting the representation of the female body as the primary side of sexuality and visual pleasure. In this paper the cinematic techniques were analyzed, especially the camera with its various types of shooting. Analyses were also conducted on the technique of lightings and costume selection. The result of the analyses shows that the cinematic techniques, either the types of shots or the lightings were used to expedite the male gaze and exploit the female body for the sake of visual pleasure. The camera is used as an operating means of eyeing desire (voyeur gaze). Women were positioned as the objects of the male gaze adherent to the gaze of the camera (male gaze). Cinematic techniques constructed women as objects of male gaze for the people behind the production as well as the audience.

Keywords: male gaze, cinematic techniques, women, object of sexuality

\section{PENDAHULUAN}

Film horor kali pertama dibuat berjudul "Le Manoir Du Diable" yang berarti rumah hantu. Film ini dibuat oleh George Melies dan dirilis di Amerika (United States) dengan nama
'The Haunted Castle' dan di Inggris (Britain) dengan nama 'The Devil's Castle' pada tahun 1986. Film ini berisi adegan-adegan pantomim dengan durasi tiga menit, karena masih era film bisu (https://en .m.wikipedia.org/wiki/ 
The_Haunted_castle_(1896_film, diakses pada 4 Januari 2016, pukul 23.00 WIB). Tujuan film bisu pendek Perancis ini lebih untuk menghibur daripada menakuti penonton.

Kelahiran pertama genre horor di Paris pada 1896 tersebut seiring dengan penerimaan publik atas teori psikoanalisis Sigmund Freud, yaitu sebuah teori yang mengeksploitasi hasrat terpendam manusia di alam bawah sadar kali (www.academia.edu/7906150/Film_Horor Indonesia_menertawakan_Ketakutan ditulis oleh Maulin Ni'am dan Nella A. Puspitasari, diakses pada 28 Oktober 2015, pukul 15.55 WIB). Menurut Ernest Jones (2005) yang dikutip Carrol (1990:169), horor menjadi saluran langsung ke dorongan alam bawah sadar, yaitu ketakutan, cinta, penderitaan, dan kehilangan. Ketakutan seringkali diekspresikan dengan penggambaran monster, kekejaman, atau balas dendam.

Menurut Carroll (1990:55-56), genre horor di Eropa merupakan produk dari sastra gotik yang muncul pada pertengahan abad ke-18 di Inggris dan Jerman. Kemunculan sastra gotik ini erat kaitannya dengan dominasi rasionalisme dan perkembangan ilmu pengetahuan yang menjunjung tinggi nilai objektif. Sastra gotik muncul mewakili sisi gelap abad pencerahan pada masa itu yang menyembunyikan kecenderungan-kecenderungan imajinatif, irasional, subjektif, dan dekat dengan hal-hal supranatural.

Freeland mengartikan horor sebagai sesuatu yang berusaha mengeksploitasi segala bentuk kejahatan (Livingstone dan Plantinga, 2009:46). Sementara itu menurut Vincent Pinell dalam buku Genres et Mouvements au Cinéma (2006:124), film horor adalah film yang penuh dengan eksploitasi unsur-unsur horor yang bertujuan untuk membangkitkan ketegangan penonton. Genre ini mencakup sejumlah subgenre dan tema-tema yang terus berulang, seperti pembunuhan berantai, vampire, zombie, kesurupan, teror makhluk asing, kanibalisme, rumah angker, dan sebagainya. (http://staff. ui.ac.id/system/files/users/suriella/publication/ filmhororindonesia.pdf, diakses pada 4 Januari 2016, pukul 21.20 WIB).

Film horor di Indonesia menjadi salah satu genre film yang digemari oleh masyarakat Indonesia. Pada 1970-an, film horor juga menjadi pilihan yang banyak disukai seperti film-film yang diperankan oleh Suzanna. (www.academia.edu/7906150/Film_Horor_ Indonesia_menertawakan_Ketakutan, diakses pada 3 Januari 2016, pukul 10.16 WIB). Beberapa film tersebut di antaranya berjudul Bernafas dalam Lumpur (1970), Beranak dalam Kubur (1971), Pulau Cinta (1978), dan Ratu Ilmu Hitam (1981). Selain itu, juga film horor Si Manis Jembatan Ancol yang dikenal dengan hantu perempuan yang cantik dan seksi diperankan oleh Diah Permata Sari dan Kiki Fatmala. Pada era tahun 1990-an perfilman di Indonesia sempat meredup bahkan mengalami kevakuman. Hal ini dikarenakan kehadiran televisi swasta yang semakin banyak menyuguhkan film dalam tayangan mereka sehingga membuat film bioskop kehilangan daya tarik (www.academia.edu/7906150/Film_ Horor_Indonesia_menertawakan_Ketakutan, diakses pada 3 Januari 2016, pukul 11.16 WIB) termasuk genre film horor.

Kebangkitan film horor terjadi sejak 2001 ketika Jose Poernomo (produser dan sutradara) bersama Rizal Mantovani (sutradara dan penulis skenario) memproduksi sebuah film horor kontemporer berjudul Jelangkung (www.academia.edu/7906150/Film_Horor_ Indonesia_menertawakan_Ketakutan, diakses 
pada 3 Januari 2016, pukul 13.08 WIB) yang berhasil menembus perhatian masyarakat Indonesia terhadap genre film horor.

Pascareformasi, film horor mengalami pergeseran, yaitu pemain dan segmentasinya difokuskan pada remaja. Kebanyakan ceritanya berisi percintaan yang dibalut dengan kisah horor. Pasca melejitnya film Jelangkung, produksi film horor kian menjamur. Beberapa contoh film yang diproduksi di antaranya Tusuk Jelangkung, Tali Pocong Perawan, Hantu Setan Budeg, Kuntilanak, dan Air Terjun Pengatin. Beberapa film horor ini berbeda dengan film horor era 70-an hingga sebelum reformasi dimana filmnya lebih serius. Banyak pula yang memasukkan adegan humor dalam film horor yang diproduksi pada era pascareformasi. Pada era pascareformasi, produksi film horor dengan suguhan adegan humor kian menjamur. Salah satu faktor yang berkontribusi adalah kondisi politik pada pascareformasi berbeda dengan masa Orde Baru. Pada masa Orde Baru semua tayangan difilter dengan ketat, sedangkan era pascareformasi jauh lebih bebas. Kebebasan tayangan pada masa pascareformasi memengaruhi beberapa film horor memilih menyuguhkan adegan dan kostum yang lebih vulgar, misalnya adegan menurunkan celana dalam di lokasi pemakaman dalam film berjudul Setan Budeg yang diperankan Dewi Persik, atau adegan ranjang yang ditampilkan dalam beberapa film horor. Selain itu, pilihan kostum cenderung terbuka seperti hot pant dan tank top atau bikini yang seringkali diselipkan dalam film horor, seperti salah satunya dalam film Pacar Hantu Perawan.

\section{SINOPSIS FILM PACAR HANTU PERAWAN}

Film horor yang akan dibahas adalah salah satu film yang diperankan oleh Dewi Persik berjudul Pacar Hantu Perawan. Film yang diproduseri oleh KK Dheraj, dan disutradarai oleh Yoyok Dumprink dirilis 6 Oktober 2011. Film ini mengisahkan tiga perempuan saudara kandung, yaitu Mandy, Misa, dan Vicky. Mandy diperankan oleh Dewi Persik sebagai tokoh utama. Film ini diwarnai hadirnya bintang film porno asal Amerika, yaitu Vicky Vette yang memerankan Vicky, dan model seksi asal Philipina Misa Campo yang memerankan tokoh Misa.

Cerita dalam film ini diawali dengan perjalanan Mandy berwisata bersama sahabat sekaligus manajernya bernama Joyce yang diperankan oleh Natha Narita dan pacarnya bernama Alex yang diperankan oleh Rafi Cinoun ke sebuah hutan. Tempat itu dijuluki Hutan Jodoh karena memiliki pancuran yang konon bisa memperat jodoh. Dipercayai bahwa siapa yang mandi di pancuran itu akan segera mendapatkan jodoh. Joice menceritakan bahwa dirinya menemukan Alex setelah melakukan ritual mandi di pancuran itu. Mandy tidak percaya hal-hal yang dia anggap takhayul, kemudian Mandy mandi di pancuran keramat tanpa melakukan ritual mencari jodoh. Seusai mandi, Mandy mengitari hutan di sekitar pancuran dan bertemu dengan Romy yang diperankan oleh Jonathan Frizzy. Mereka saling terpikat dan jatuh cinta. Mandy tidak menyadari bahwa Romy adalah sosok hantu laki-laki yang muncul akibat Mandy mandi di pancuran tanpa melakukan ritual.

Dalam film itu dikisahkan Opa Mandy meninggal sehingga membuat Mandy sangat kehilangan. Akan tetapi, dirinya sangat terhibur dengan kehadiran Romy yang selalu menemani. Mandy menjadi sangat sayang kepada Romy. Di sisi lain teman-teman Mandy merasa ada 
keanehan pada diri Mandy namun hal itu tidak disadari oleh Mandy. Mandy sering berbicara sendiri seolah-olah ada teman yang dia ajak bicara, namun kehadiran lawan bicara tidak terlihat oleh teman-temannya. Joyce dan Alex yang menjadi teman dekat Mandy berusaha menyadarkan Mandy dengan menunjukkan bahwa Romy itu bukanlah manusia. Dalam upaya pembuktian, Joyce dan Alex bertemu dengan Yoga (yang diperankan oleh Olga Saputra). Yoga menceritakan semua kisah Romy dan akhirnya menguak siapa sosok Romy dan kaitannya dengan pancuran di Hutan Jodoh tersebut.

Cerita film ini sangat sederhana. Film ini bukan film horor serius yang menegangkan dan menakutkan. Dalam film ini seringkali diselipkan adegan humor, misalnya pocong hadir bukan untuk menakut-nakuti, namun pocong ditampilkan justru untuk tujuan humor misalnya ekspresi wajah pocong tiba-tiba muncul sedang mengintip Mandy yang sedang mandi atau pocong hadir dengan ekspresi 'mupeng' (muka pengen) sedang mengagumi kemolekan tubuh Mandy. Hal yang ditekankan dalam film ini bukan pada ceritanya yang menarik ataupun kualitas gambar dan filmnya, namun lebih pada seringnya muncul adegan mandi, adegan di ranjang, atau di tempat lain seperti kolam renang dengan pakaian seksi yang mempertontonkan tubuh pemain utama, yaitu Dewi Persik, Vicky Vette, dan Misa Campo. Permainan sudut pandang (angle) kamera dan pengambilan gambar didukung dengan permainan pencahayaan (lighting) memosisikan tubuh perempuan sebagai objek pandangan bagi penonton. Selain itu, didukung pilihan kostum yang digunakan para pemain adalah jenis pakaian yang seksi dan transparan yang menunjukkan lekuk tubuh perempuan.
Fokus pembahasan dalam tulisan ini bukan pada cerita dalam film, namun lebih pada teknik sinematik yang digunakan. Khususnya teknik pengambilan gambar (type of shot) dan pencahayaan (lighting) yang dipilih dalam film tersebut. Teknik sinematik ini digunakan untuk menganalisis bagaimana hasrat memandang laki-laki (male gaze) beroperasi dalam film Pacar Hantu Perawan.

Tuchman (1979:51) mengatakan bahwa perempuan dalam pandangan lakilaki adalah sebagai objek seksual. Perempuan dihadirkan dalam media, namun tidak lepas hanya sebagai objek seksual bagi laki-laki. Lauretis (1987:13) menjelaskan bagaimana perempuan menjadi objek hasrat bagi penonton (voyeurist gaze). Menurut Lauretis, sangat penting melihat unsur teknik sinematik yang digunakan media dalam melihat bagaimana media memosisikan perempuan. Teknik sinematik yang dimaksud antara lain lighting, editing, dan framing. Selain itu, juga perlu memahami kode sinematik khusus, yaitu sistem memandang. Dalam hal ini adalah bagaimana perempuan ditampilkan oleh media tersebut dipandang dan diposisikan. Dalam sejumlah sinema atau film, Lauretis menjelaskan bahwa teknik sinematik mengonstruksi perempuan sebagai objek hasrat pandangan bagi penonton dengan menggarisbawahi representasi tubuh perempuan sebagai sisi utama seksualitas dan kesenangan visual.

Begitu pula Mulvey (1975:808) menjelaskan bahwa perempuan sering ditempatkan sebagai objek hasrat pandangan bagi laki-laki: "In a world ordered by sexual imbalance, pleasure in looking has been split between active male and passive female. The determining male gaze its fantasion to the which is styled accordingly". 
Sejalan dengan Tuchman, Mulvey (1975:809) mengatakan bahwa perempuan ditampilkan sebagai objek seksual: "Women displayed as sexual object is the leit-motif of erotic spectacle from pin-ups to strip tease iegfeld to Busby Barkeley she holds the look, plays to and signifies male desire”.

Dalam media, mata kamera diibaratkan sebagai mata laki-laki sehingga tampilan perempuan dalam media cenderung patuh pada kontrol tatapan mata laki-laki. Posisi laki-laki merupakan subjek aktif, sedangkan perempuan sebagai subjek pasif. Perempuan tidak diposisikan sebagai subjek yang memiliki kuasa atas dirinya sendiri atau memiliki kapasitas diri (self-possessiveness), tetapi seringkali diposisikan sebagai objek bagi hasrat laki-laki (male gaze). Hal ini juga dapat digunakan untuk memahami bagaimana perempuan ditampilkan dalam film horor di Indonesia dan sebagaimana teknik sinematik digunakan untuk melancarkan harat memandang laki-laki (male gaze) terhadap perempuan.

\section{KAMERA SEBAGAI ALAT OPERASI MALE GAZE}

Film horor menjadi salah satu genre film yang digemari masyarakat Indonesia, temasuk remaja yang menjadi sasaran para produser film. Berbagai film horor diproduksi baik film horor yang serius dan menegangkan maupun film horor yang juga menyelipkan aspek humor. Teknik sinematik mulai dari teknik pengambilan gambar (type of shoot) dan pencahayaan (lighting) yang digunakan dalam produksi film horor sangat dibutuhkan untuk menciptakan kesan dan nuansa menegangkan dan menyeramkan. Dalam pembahasan ini akan dianalisis bagaimana teknik pengambilan gambar dan pencahayaan dalam film Pacar
Hantu Perawan untuk memahami bagaimana teknik sinematik digunakan untuk melancarkan hasrat memandang laki-laki terhadap perempuan. Dalam pemahaman ini juga akan dianalisis faktor pendukung dalam produksi film tersebut, yaitu pemilihan kostum.

\section{Teknik Pengambilan Gambar}

Film horor yang kental dengan suguhan adegan menegangkan seringkali menggunakan teknik pengambilan gambar cut to cut yang diselipkan untuk memberikan kesan mengagetkan penonton, misalnya sosok hantu yang tiba-tiba muncul didukung musik ilustrasi yang menyeramkan dan menegangkan. Teknik pengambilan gambar yanng digunakan di antaranya medium shot, close up, knee shot, extreme close up, full shot, long shot, dan wide shot untuk menunjukkan tokoh ataupun lokasi tempat adegan dalam film tersebut. Sering pula teknik pengambian gambar pan left/right, track left/right, dan tilt up/down digunakan untuk menunjukkan situasi misalnya track right/left dari ruang satu ke ruangan di sampingnya yang dibatasi dinding untuk menunjukkan situasi misalnya ada sosok hantu di ruang sebelah.

Akan tetapi, dalam Film Pacar Hantu Perawan, teknik pengambilan gambar seringkali digunakan untuk mengekploitasi tubuh perempuan. Beberapa teknik pengambilan gambar yang digunakan untuk mengeksploitasi tubuh perempuan di antaranya:

\section{a. Long Shot}

Pemilihan teknik pengambilan gambar long shot digunakan untuk menggambarkan situasi di sekitar objek yang dibidik oleh kamera. Selain itu, untuk menunjukkan tempat lokasi objek tersebut berada. Seperti adegan awal dalam film dengan lokasi di kamar tidur untuk 
memperlihatkan situasi di sekitar ranjang. Akan tetapi, sebenarnya tidak hanya itu. Dalam film ini long shot juga dipilih untuk menunjukkan agar semua gerak gerik dan gesture tubuh objek dalam hal ini adalah tubuh perempuan yang dibidik tidak lepas dari kamera. Seperti dalam gambar 1 dan 2.

Visual adegan ini muncul pada scene pertama. Setting lokasi berada di kamar tidur dan adegan perempuan dengan pakaian transparan yang terlihat dada, payudara, dan paha. Pengambilan gambar long shot perempuan yang sedang bangun tidur kemudian menggeliatkan tubuhnya yang montok dan seksi. Hal ini dapat diamati dalam gambar 3 dan 4 .

Selanjutnya perempuan tersebut berjalan dari tempat tidur menuju jendela tempat cahaya di luar jendela lebih terang dibanding cahaya di dalam kamar. Dalam adegan tersebut perempuan itu tidak berdiam diri, namun sambil menggoyangkan pinggul, pantat, dan paha menuju jendela dengan cahaya yang lebih terang sehingga lekuk tubuhnya semakin terlihat jelas. Ditambah dengan pemilihan pakaian berwarna putih transparan, hal ini semakin menunjukkan keseksian dan kemolekan tubuhnya. Teknik sinematik pencahayaan juga digunakan untuk memosisikan perempuan sebagai objek seksual laki-laki. Teknik pengambilan gambar yang digunakan juga long shot seperti gambar 5, 6 dan 7.

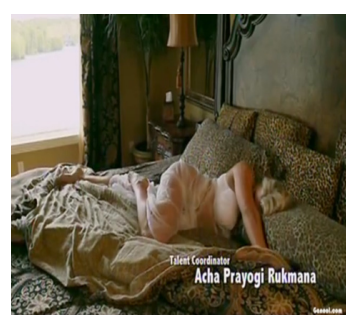

Gambar 1

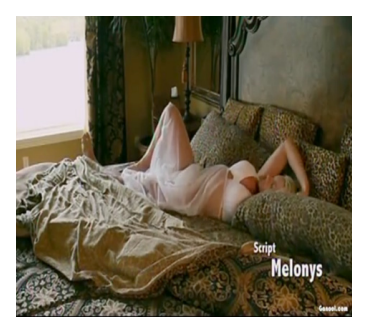

Gambar 2

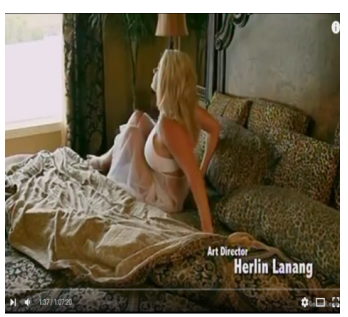

Gambar 3

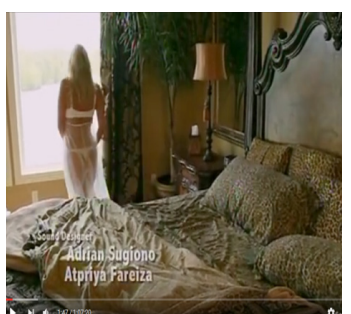

Gambar 5

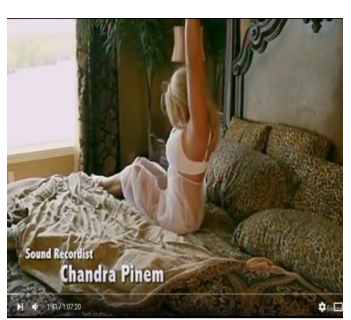

Gambar 4

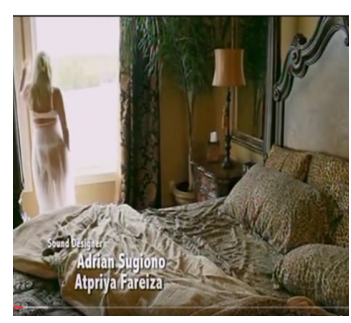

Gambar 6

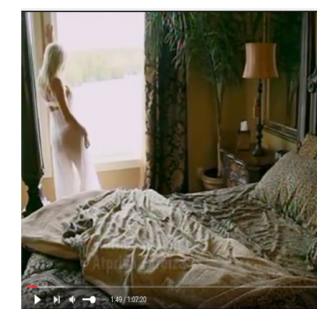

Gambar 7

Kamera yang dioperasikan bukan still video/ still foto (gambar diam), namun kamera digunakan untuk membidik perempuan di atas ranjang dengan teknik pengambilan gambar moving dan tipe pengambilan gambar long shot mulai dari tidur kemudian setiap gerakan di ranjang hingga perempuan berdiri dan berjalan menuju jendela. Kamera bagaikan mata lakilaki yang tidak berkedip mengawasi bahkan menikmati setiap gerakan dan lekuk tubuh perempuan. Perempuan menjadi objek hasrat seksual bagi penonton (voyeurist gaze).

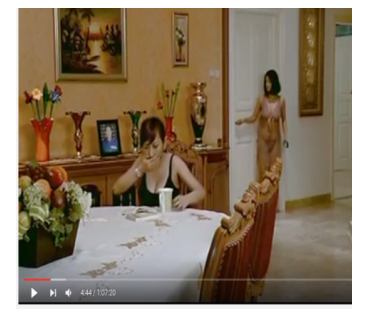

Gambar 8

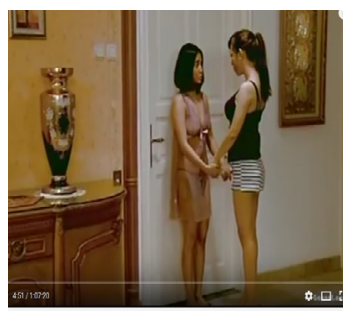

Gambar 9 
Begitu pula gambar 8 dan 9 ketika Dewi Persik keluar kamar dan berdiri di depan pintu kamar. Tipe pengambilan gambar dipilih long shot bukan semata-mata untuk menangkap dua objek sekaligus, Joice dan Dewi Persik, namun kamera tetap digunakan untuk mengambil gambar tubuh Dewi persik yang menggunakan lingery, dan baju transparan. Kamera kembali digunakan untuk melancarkan hasrat memandang laki-laki terhadap tubuh perempuan.

\section{b. Knee Shot}

Selain tipe pengambilan gambar long shot, knee shot juga digunakan untuk membidik tubuh perempuan seperti gambar 10, 11, dan 12 .

Mulai dari gambar 8 hingga 10 , gambar perempuan yang ditampilkan secara teknik pengambilan gambar tidak tepat karena memotong bagian kepala objek (headroom). Dari penilaian kualitas gambar, jelas gambar ini tidak memenuhi kaidah gambar yang baik, namun gambar ini tetap digunakan. Memang fokus film ini bukan pada kualitas gambar sesuai teknik pengambilan gambar, namun kamera lebih difokuskan untuk membidik tubuh perempuan seksi dengan baju transparan dan gesture tubuhnya yang menantang (erotic spectacle). Kamera digunakan lebih untuk mengeksploitasi tubuh perempuan dan melancarkan hasrat memandang laki-laki terhadap perempuan dengan menggunakan kamera. Kamera digunakan untuk mengintip kemolekan tubuh perempuan. Perempuan menjadi objek hasrat bagi penonton (voyeurist gaze), seperti yang disampaikan Mulvey bahwa posisi laki-laki merupakan subjek aktif, sedangkan perempuan sebagai subjek pasif. Perempuan tidak diposisikan sebagai subjek yang memiliki kuasa atas dirinya sendiri atau

memiliki kapasitas diri (self-possessiveness), tetapi diposisikan sebagai objek bagi hasrat seksual laki-laki (male gaze).

Teknik sinematik yang digunakan untuk melancarkan hasrat seksual ini didukung dengan pengaturan pencahayaan (lighting). Pencahayaan diatur agar cahaya dari luar jendela lebih terang dibanding cahaya dari dalam kamar. Hal ini menimbulkan efek siluet sehingga gesture dan gerakan erotis tubuh perempuan semakin jelas hingga bayangan cahaya di sela selangkang.

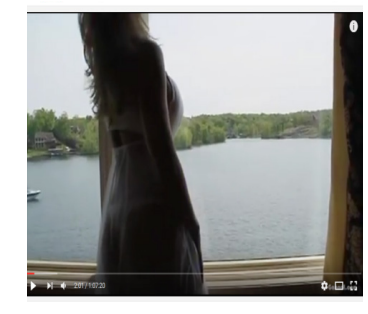

Gambar 10

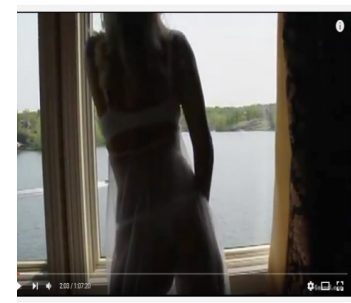

Gambar 11

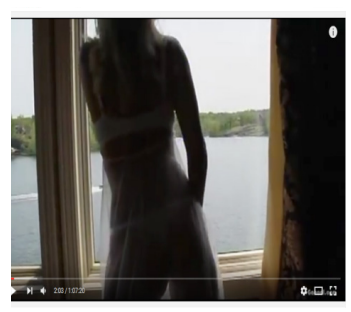

Gambar 12

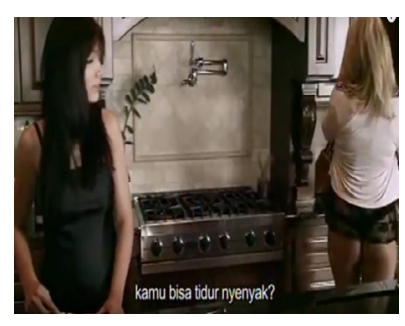

Gambar 13

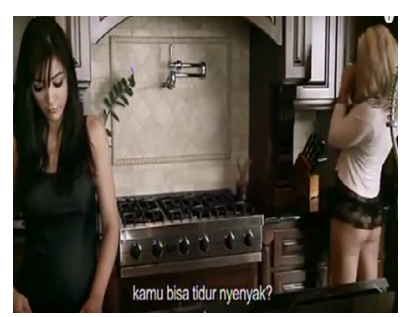

Gambar 14

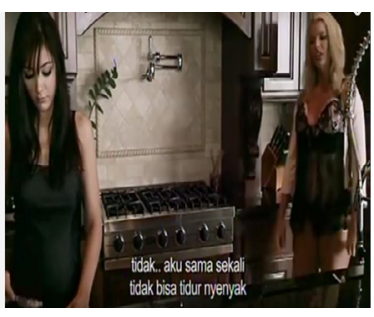

Gambar 15 
Adegan di dapur dalam gambar 13, 14 dan 15 memilih tipe knee shot bukan tanpa alasan. Knee shot digunakan agar dapat membidik tubuh Vicky yang berpakaian sangat terbuka terutama di bagian pantat. Hal ini terlihat dari adegan Vicky yang berjalan membelakangi kamera dan tertangkap oleh kamera di bagian pantat. Tipe ini kembali digunakan untuk melancarkan hasrat memandang laki-laki (male gaze) terhadap tubuh perempuan. Kembali perempuan menjadi objek dan kesenangan seksualitas bagi fantasi seksual laki-laki.

\section{b. Medium Shot dan Close Up}

Dalam film Pacar Hantu Perawan, teknik pengambilan gambar medium shot dan close up sangat sering muncul. Tidak sedikit teknik ini dipilih dan digunakan untuk membidik objekobjek perempuan, baik wajah atau anggota tubuh seperti dada, pingul, perut, dan paha. Sebagai contoh dalam gambar 16 dan 17 dapat diamati bagaimana kamera digunakan untuk membidik anggota tubuh perempuan mulai dari ekspresi wajah perempuan yang sedang berjoged dengan mulut menganga dan tangan yang sedang menyentuh payudara. Kemudian dalam gambar 18, 19 dan 20 memiliki tipe pengambilan gambar medium shot dan close up untuk mengeksploitasi tubuh perempuan.

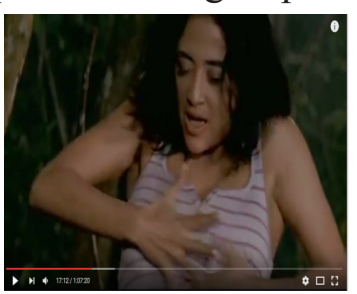

Gambar 16

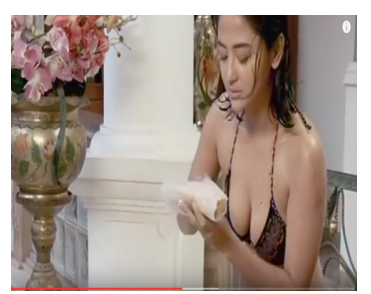

Gambar 18

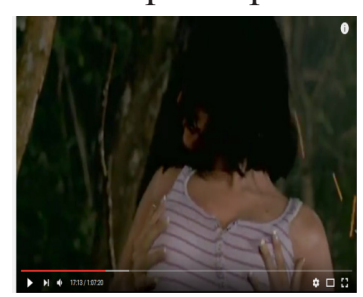

Gambar 17

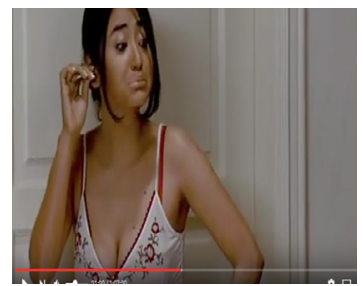

Gambar 19

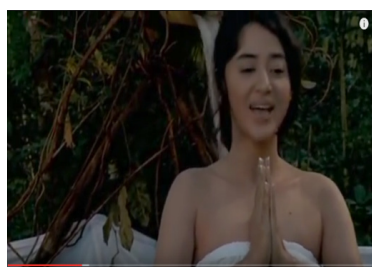

Gambar 21

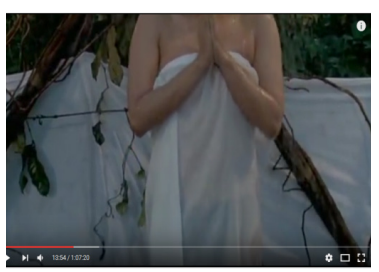

Gambar 23

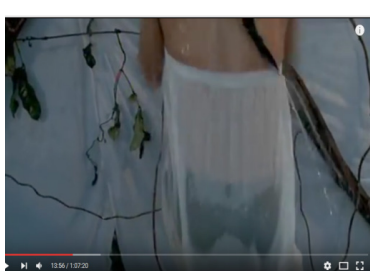

Gambar 25

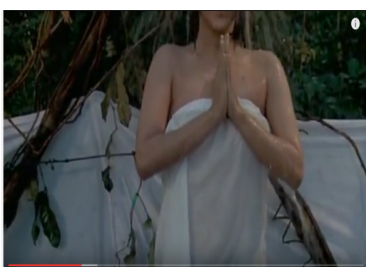

Gambar 22

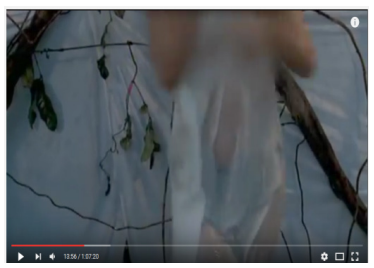

Gambar 24

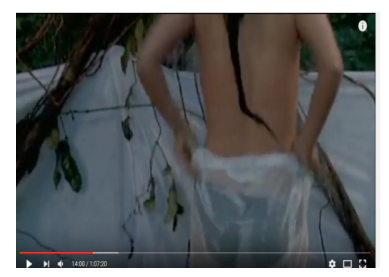

Gambar 26 


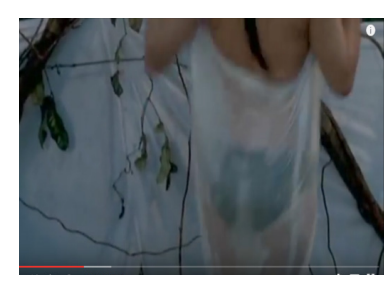

Gambar 27

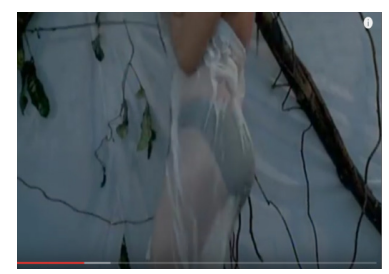

Gambar 29

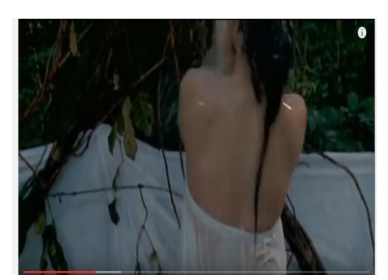

Gambar 28

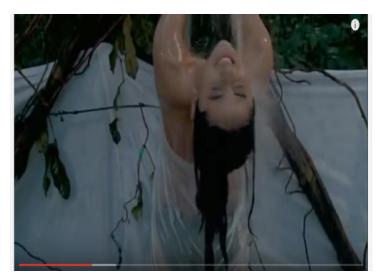

Gambar 30
Dalam gambar 21 ditampilkan medium shot Dewi Persik kemudian tipe pengambilan gambar (type of shot) tilt down mulai pada gambar 22 menampilkan gambar tubuh Dewi Persik dengan batasan leher hingga bagian bawah perut. Selanjutnya tilt down ke gambar 23 , leher sudah tidak terlihat dan batas bagian bawah adalah bawah selangkang. Gambar Dewi Persik dengan pakaian transparan putih dan celana dalam warna hitam kontras dengan kain yang digunakan untuk menutupi tubuhnya ketika mandi. Dalam gambar ini segitiga celana dalamnya sudah mulai terlihat. Selanjutnya gambar 25 menampilkan posisi tubuh Dewi Persik memutar dan membelakangi kamera. Pantat Dewi Persik terlihat jelas dilanjutkan adegan menurunkan kain putih seolah-olah mau dilepas, namun hanya sampai pinggang dan posisi kain putih tetap menutupi bagian pantat. Moving kamera tilt down berhenti sampai ke gambar ini kemudian dilanjutkan tilt up. Hal ini menunjukkan bahwa yang menjadi fokus gambar yang dibidik adalah tubuh perempuan terutama di bagian perut, pinggang, punggung, paha, dan pantat. Selanjutnya gambar mulai tilt up ke bagian pantat dan punggung seperti dalam gambar 27 dan 28. Gerakan-gerakan erotis yang ditampilkan dengan menggoyang-goyangkan badan terus dilakukan hingga gambar 29 dan 30.
Tipe pengambilan gambar tilt down juga dipilih untuk melancarkan hasrat memandang demi kesenangan visual seperti gambar 31-35.

Dari gambar 31 hingga 35 dapat diamati bagaimana kamera dengan tipe pengambilan gambar tilt down digunakan untuk menatap tubuh perempuan untuk kesenangan visual. Mulai dari gambar wajah dan badan dalam gambar 31 kemudian tilt down ke bagian payudara, dada, dan perut dalam gambar 32, selanjutnya tilt down ke bagian payudara, perut, dan pinggul dengan gerakan tangan membuka ritsluiting dan membuka kancing celana seperti dalam gambar 33 sampai 35.

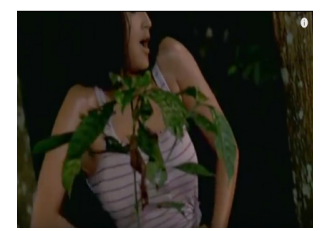

Gambar 31

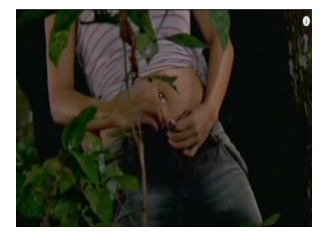

Gambar 33

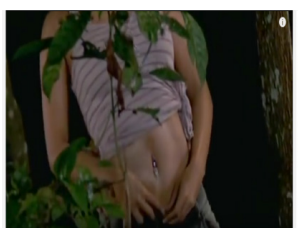

Gambar 32

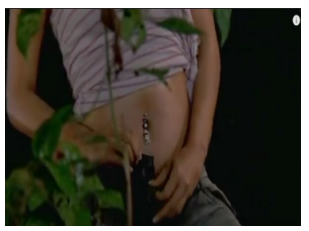

Gambar 34

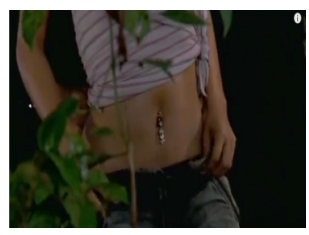

Gambar 35

\section{d. Pan Right dan Pan Left}

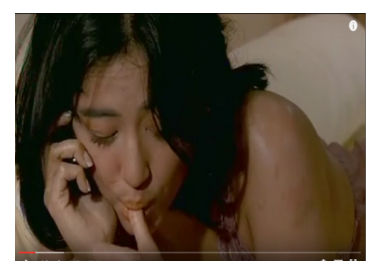

Gambar 36

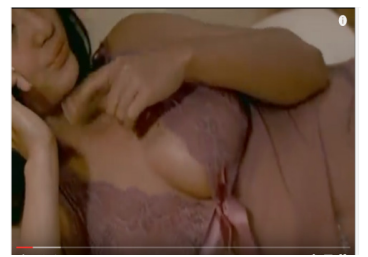

Gambar 37 


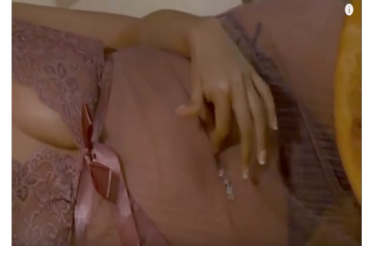

Gambar 38

Selain tilt up dan tilt down, pergerakan kamera moving pan juga dipilih untuk kembali mengekploitasi tubuh perempuan. Hal ini muncul ketika adegan Dewi Persik sedang menelepon saudaranya yang berada di Amerika. Pergerakan moving pan right dapat diamati dari gambar 36 yang menunjukkan close up wajah Dewi Persik kemudian mulai pan right dalam gambar 37 yang menampilkan wajah dan lengan serta bagian dada, payudara, dan perut. Visual berakhir dalam gambar 38 dengan menampilkan komposisi gambar bagian payudara, perut, hingga bagian atas celana dalam yang ditampilkan dalam satu frame. Dalam adegan ini Dewi Persik memainkan jari tangannya dengan memutarkan jarinya melingkari pusar. Adegan ini bukan tanpa maksud. Gerakan ini untuk memancing tatapan penonton agar pandangan fokus di bagian perut Dewi Persik yang menggunakan pakaian transparan dan terbuka.

Dari pembahasan tersebut dapat dipahami bahwa teknik sinematik berupa tipe pengambilan gambar dan pencahayaan (lighting) yang dipilih dan digunakan dalam film ini justru memosisikan perempuan sebagai objek bagi hasrat pandangan laki-laki (male gaze). Wajah dan tubuh perempuan menjadi objek seksualitas bagi penonton dan juga orangorang di balik produksi film tersebut. Kamera sebagai alat sinematik menjadi senjata untuk melancarkan male gaze. Kamera menjadi alat untuk mengeksploitasi tubuh perempuan sebagai objek hasrat seksualitas dan kesenangan visual bagi laki-laki. Perempuan dan tubuh perempuan seolah-olah tunduk terhadap tatapan kamera. Mata kamera diibaratkan mata laki-laki sehingga tampilan perempuan dalam media (sinema) cenderung patuh terhadap kontrol tatapan mata laki-laki. Hal ini seperti yang disampaikan Tuchman, Lauretis, dan Mulvey bahwa kode sinematik khusus, yaitu sistem memadang dalam film tersebut hanya memosisikan perempuan sebagai objek hasrat pandangan bagi laki-laki. Perempuan tidak diposisikan sebagai subjek yang memiliki kuasa atas dirinya sendiri atau tidak memiliki kapasitas (self-possesiveness). Seperti disampaikan Lauretis bahwa teknik sinematik mengonstruksi perempuan sebagai objek hasrat pandangan bagi penonton dengan menggarisbawahi representasi tubuh perempuan sebagai sisi utama seksualitas dan kesenangan visual.

\section{Pemilihan Kostum}

Pemilihan kostum merupakan aspek yang sangat penting dalam sebuah film karena merepresentasikan sosok tokoh yang diperankan dalam film tersebut. Akan tetapi, berbeda dengan film Pacar Hantu Perawan, pemilihan kostum terutama bagi tokoh-tokoh perempuan cenderung pakaian yang terbuka seperti celana pendek (hotpants), lingerien, bra, dan pakaian transparan dengan warna-warna yang mirip dengan warna kulit seperti soft pink kecokelatan, putih, atau warna menantang seperti merah dan hitam. Bahan yang dipilih cenderung transparan seperti hem putih atau brokat tipis dan transparan. Pemilihan model dan bahan pakaian ini bukan tanpa alasan, namun untuk mendukung agar bidikan kamera terhadap tubuh perempuan dapat dilakukan. Selain itu, agar cahaya (lighting) yang telah diatur dapat menembus bagian tubuh dan 
kamera mampu membidik setiap lekuk tubuh perempuan. Pemilihan pakaian terbuka ini dilakukan agar setiap lekuk tubuh perempuan dapat dinikmati sebagai objek seksual dan kesenangan visual.

\section{SIMPULAN}

Film horor yang digunakan untuk membangkitkan ketegangan penonton cenderung tidak dihadirkan, namun film horor justru menjadi media ekploitasi tubuh perempuan. Persentase kehadiran hantu sangat sedikit seperti kuntilanak atau pocong. Kehadiran sosok hantu bukan menjadi inti cerita untuk menciptakan unsur ketegangan dan ketakutan, namun sebagai selingan untuk mendukung sisi humor dalam film. Kehadiran hantu sama sekali tidak mendukung unsur ketegangan layaknya film horor.

Teknik sinematik bukan digunakan untuk kebutuhan seni dalam pengambilan gambar atau untuk menggambarkan kondisi dan situasi yang mendukung inti cerita, tetapi teknik sinematik baik teknik pengambilan gambar (type of shot) maupun pencahayaan justru digunakan untuk melancarkan hasrat memandang laki-laki dan mengeksploitasi tubuh perempuan demi kesenangan visual.

Teknik sinematik yang digunakan dalam sebuah film menunjukkan representasi dan posisi perempuan. Dalam film horor Pacar Hantu Perawan, perempuan diposisikan sebagai objek bagi pandangan laki-laki yang patuh terhadap tatapan mata kamera (tatapan mata laki-laki). Teknik sinematik mengonstuksi perempuan sebagai objek hasrat pandangan bagi orang-orang di balik produksi dan penonton dengan menggarisbawahi representasi tubuh perempuan sebagai sisi utama seksualitas dan kesenangan visual.

\section{KEPUSTAKAAN}

Carroll, Noel. 1990. The Philosophy of Horror. New York: Routledge.

Lauretis, Teresa de. 1987. Technologies of Gender, Essays on Theory, Film and Fiction. Bloomington dan Indianapolis: Indiana Univercity Press.

Livingstone, Paisley \& Carl Plantinga. 2008. The Routledge Companion to Philosophy and Film. London: Routledge.

Mulvey, Laura. 1975. Visual Pleasure and Narrative Cinema (A Rewarded Version of a Paper Given in the French Department of the University of Wisconsin, Madison, in the Spring of 1973).

Tuchman, Gaye. 1979. "Women's Depiction by the Mass Media”. Sign. 4: 528-542.

\section{Pustaka Laman}

www.academia.edu/790610/Film_Horor_ Indonesia_Menertawakan_Ketakutan, diakses pada 3 Januari 2016, pukul 10.16 WIB.

http://staff.ui.ac.id/system/files/users/suriella/ publication/filmhororindonesia.pdf, diakses pada 4 Januari 2016, pukul 21.20 WIB.

https:/en.m.wikipedia.org/wiki/The Haunted Castle_(1896_film), diakses pada $\overline{4}$ Januari 2016, pukul 23.00 WIB. 
